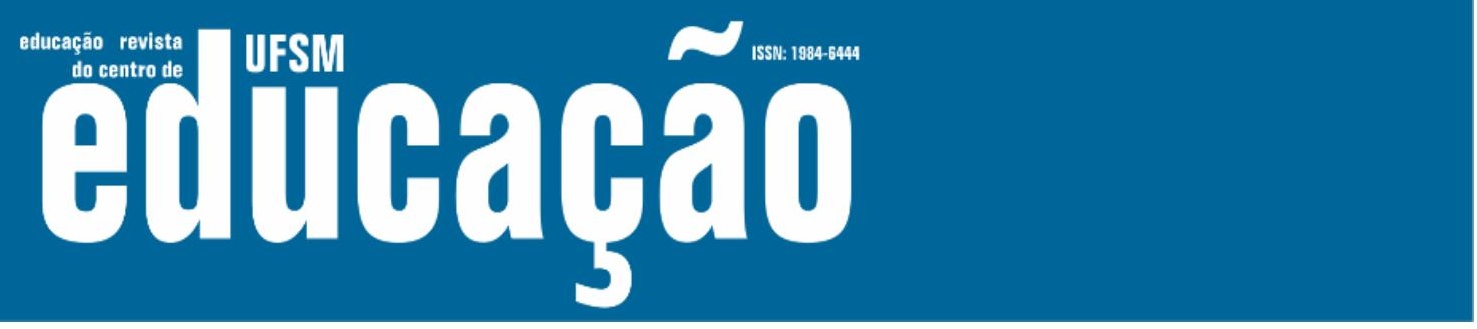

ISSN: 1984-6444 | http://dx.doi.org/10.5902/1984644461413

\title{
As matrículas na Educação de Jovens e Adultos no Ensino Médio em meio à crise da ideologia neodesenvolvimentista
}

\author{
Youth and Adult Education in Secondary School Enrollments amid the \\ Neo-Developmentalist ideology crisis
}

Jaqueline Pereira Ventura

Professora adjunta na Universidade Federal Fluminense, Niterói, Rio de Janeiro, Brasil.

jaquelineventuraja@gmail.com - https://orcid.org/0000-0001-9548-253X

Francisco Oliveira

Professor da Faculdade de Formação de Professores da Universidade do Estado do Rio de Janeiro. São Gonçalo, Rio de Janeiro, Brasil.

francisco.oliveira.uerj@hotmail.com - https://orcid.org/0000-0002-1125-5709

Recebido em 11 de outubro de 2020

Aprovado em 23 de novembro de 2020

Publicado em 30 de março de 2021

\section{RESUMO}

O propósito deste artigo é compreender a redução das matrículas na Educação de Jovens e Adultos (EJA) no ensino médio na última década. Especificamente, investiga a oferta de EJA/ensino médio no Brasil, de 2009 a 2019, relacionando-a com alguns dos suportes que guiaram as políticas públicas para a modalidade nessa etapa da educação básica: a forma de lidar com a demanda, a flexibilização do tipo de oferta e a ampliação da certificação. Em seguida, analisa algumas das implicações dessas políticas para a educação da classe trabalhadora, em um período que abarca a crise e o colapso da ideologia neodesenvolvimentista e a ascensão dos ultraliberais ao poder. Com base nos dados quantitativos, em documentos oficiais e na literatura especializada, busca desvelar alguns dos aspectos da correlação de forças responsáveis pela redução e pela estagnação das matrículas na EJA/ensino médio no período, que resultaram no fortalecimento de ações educacionais como, por exemplo, elaborar e/ou aprimorar exames nacionais. O itinerário das políticas públicas constituído nessa correlação de forças demonstrou que tais ações incentivaram a certificação, potencializando o mercado da educação não formal. Conclui-se, portanto, que, seja por meios como o Exame Nacional do Ensino Médio (Enem) ou o Exame Nacional para Certificação de Competências de Jovens e Adultos (Encceja), o neoliberalismo e o neodesenvolvimentismo contribuíram para esvaziar o direito à escolarização de ensino médio de jovens e adultos da classe trabalhadora e fortaleceram os vínculos do potencial estudante da EJA com a educação não formal e, em sentido mais amplo, com o mercado de certificação. 


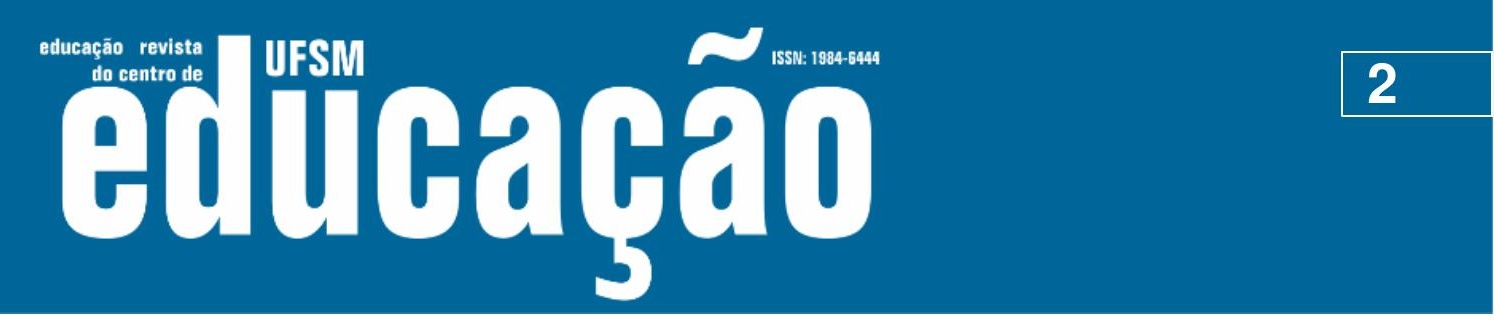

ISSN: 1984-6444 | http://dx.doi.org/10.5902/1984644461413

Palavras-chave: Educação de Jovens e Adultos; Ensino Médio; Neodesenvolmentismo.

\section{ABSTRACT}

This article aims to comprehend the decrease of enrollments in Youth and Adult Education (EJA) in secondary school in the last decade. It specifically investigates the offering of EJA/secondary schooling in Brazil from 2009 to 2019, relating it to some of the basis that guided public policies for this modality in that stage of basic education: how demand is delt with, the flexibilization of the type of offering and the expansion of certification. Next, it analyses some of the implications of those policies for the working class, in a period that encompasses the Neo-Developmentalist ideology crises and collapse and the rise of the ultraliberals to power. Based on quantitative data, documents and specialized literature, it seeks to reveal some of the aspects in the correlation of the forces responsible for the depletion and stagnation of enrollments in the EJA/secondary schooling in that period, which resulted in the strengthening of educational actions, like elaborating and/or improving national exams. The path of public policies formed by this correlation of forces has shown that such actions motivated certification, enhancing the non-formal education market. Therefore, it is concluded that, be it through means such as the National Secondary School Exam (Enem) or the National Youth and Adult Competence Certification Exam (Encceja), neo-liberalism and neo-developmentalism contributed to deflate the right to secondary education schooling of teenagers and adults of the working class and strengthened the bonds of the potential EJA student to the non-formal education and, in a broader sense, to the certification market.

Keywords: Youth and Adult Education; Secondary Education; NeoDevelopmentalism.

\section{Introdução}

A temática central deste artigo, a oferta de educação escolar de nível médio para jovens e adultos trabalhadores brasileiros ${ }^{1}$, emergiu de uma intricada e complexa crise de conjuntura: o colapso da ideologia neodesenvolvimentista e a ascensão do ultraliberalismo. A consulta dos dados de matrículas na Educação de Jovens e Adultos (EJA) para o ensino médio da última década indicava um aparente paradoxo: em vez de se acentuar a redução, tendência iniciada desde a década anterior, no auge da crise, o número de matrículas teve inesperada oscilação positiva. Compreender, para 


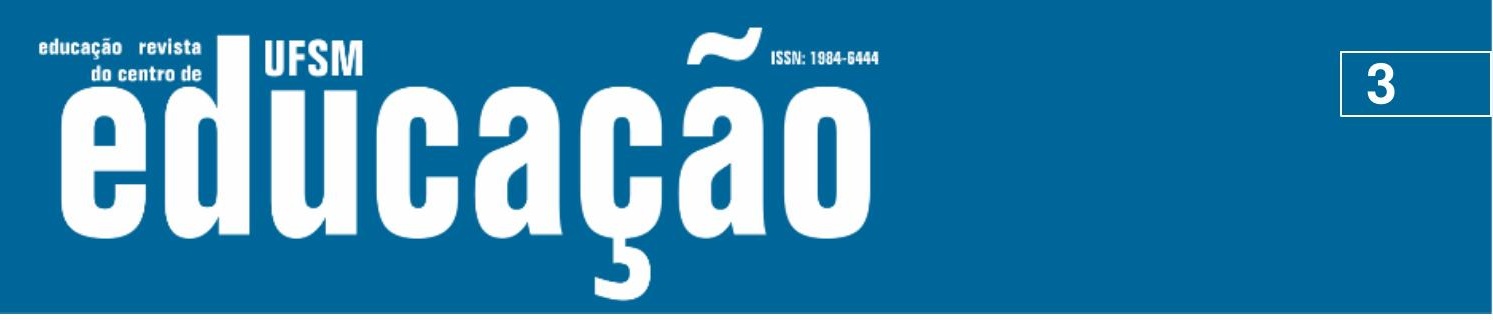

ISSN: 1984-6444 | http://dx.doi.org/10.5902/1984644461413

além da aparência, a retração das matrículas na EJA/ensino médio na última década é o objetivo deste artigo.

O estudo correlacionou os números anuais de matrículas de EJA/ensino médio do Brasil no período de 2009 a 2019 - coletados pelo Censo Escolar e sistematizados pelo Instituto Nacional de Estudos e Pesquisas Educacionais Anísio Teixeira (INEP) com a literatura da área e com outras fontes documentais, que vão de anuários estatísticos à legislação do período. Ao confrontá-los com as ações educacionais do neodesenvolvimentismo e do ultraliberalismo, verificamos a progressiva desresponsabilização do Estado com a escolarização presencial de jovens e adultos.

Portanto, embora em níveis e escalas diferentes, o estudo confirmou a continuidade entre neodesenvolvimentistas e ultraliberais na condução das políticas públicas para a EJA/ensino médio. Esta constatação se expressa no vínculo entre a tendência de retração das matrículas no ensino presencial da EJA de nível médio e a participação ativa nessa modalidade de modelos educacionais mercantis flexíveis. Assim, abre-se uma área crescente de oferta que transita da escolarização à educação não formal, própria da Educação a Distância² $(E a D)$ e dos exames nacionais de certificação.

\section{Do colapso da ideologia neodesenvolvimentista à ascensão do ultraliberalismo}

A crise econômica, política e social dos anos 1980 foi respondida, já na década de 1990, pela reestruturação do capital e pela contrarreforma do Estado Brasileiro, sob a hegemonia das teses neoliberais na gestão do Estado burguês (FRIGOTTO, 1995; FONTES, 2010). Expressões como terceirização, flexibilização, parceria público-privada, privatização, ajuste fiscal, controle de gastos e investimentos públicos etc. tornaram-se, além de populares, soluções inquestionáveis para os graves problemas que o país enfrentava e enfrenta.

Desde então, para superar as crises cíclicas do capital, o roteiro tem sido atacar os serviços públicos, o patrimônio estatal, os princípios distributivos do Estado-Nação e, principalmente, mercantilizar ainda mais os diferentes aspectos da vida social 


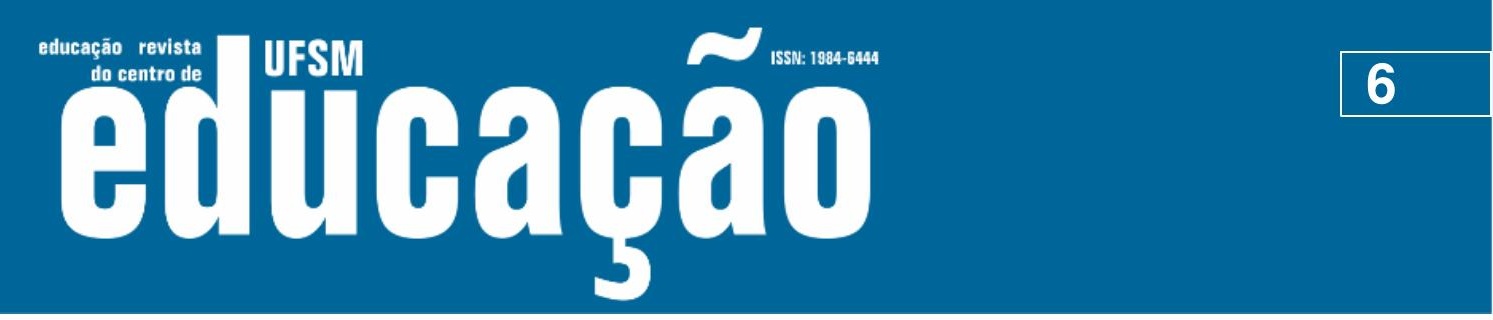

ISSN: 1984-6444 | http://dx.doi.org/10.5902/1984644461413

\section{Crise do neodesenvolvimentismo e a Educação de Jovens e Adultos}

As reformas da educação escolar no Brasil nos últimos 30 anos, embora com intensidades diferentes, não fugiram ao itinerário neoliberal. Frigotto (1995), há quase 25 anos, abordou criticamente o rejuvenescer da teoria do capital humano. Por sua vez, Neves (2004, p. 1), há quinze anos, afirmava que as reformas do final do século passado e início deste buscaram "adaptar a escola aos objetivos econômicos e político-ideológicos do projeto da burguesia mundial para a periferia do capitalismo, nesta nova etapa do capitalismo monopolista". Leher (2011, p. 1), já nesta década, afirmava que o Programa Universidade para Todos (ProUni), por meio de isenções tributárias, e o Financiamento Estudantil (FIES), por meio de juros subsidiados, significavam enorme transferência de recursos públicos às redes privadas, e sintetizava: "O Estado, ao invés de fortalecer sua rede pública, compra vagas no setor privado, para disponibilizá-las como se fossem públicas". Por fim, Saviani (2018, p. 787) constatou que "A proposta aprovada [M. P. $n^{\circ} 746 / 2016$, que versa sobre 0 ensino médio] corresponde ao intento do atual governo de ajustar a educação aos desígnios do capitalismo financeiro, buscando formar uma mão de obra dócil e a baixo custo".

As reformas da educação escolar no Brasil nos últimos 30 anos impactaram, também, a Educação de Jovens e Adultos. Ao longo da década de 1990, à histórica descontinuidade que marca a modalidade, somou-se a fragmentação das ações, desenvolvidas em programas e projetos pulverizados. Esse formato desenhou-se a partir de meados da década de 1990 e forjou uma nova identidade para a EJA (VENTURA, 2008).

Por um lado, ao aderir aos fragmentados programas federais de inspiração neoliberal, teceu uma complexa e descontínua configuração, que tem na ênfase à certificação o precário ponto de integração, e, por outro, paralelamente, arrefeceu as já modestas iniciativas, legalmente exigidas, de escolarização de jovens e adultos dos governos estaduais e municipais. Em suma, a modalidade continuou a ser tratada como um "direito de segunda categoria" (HADDAD; XIMENES, 2014, p. 254). 


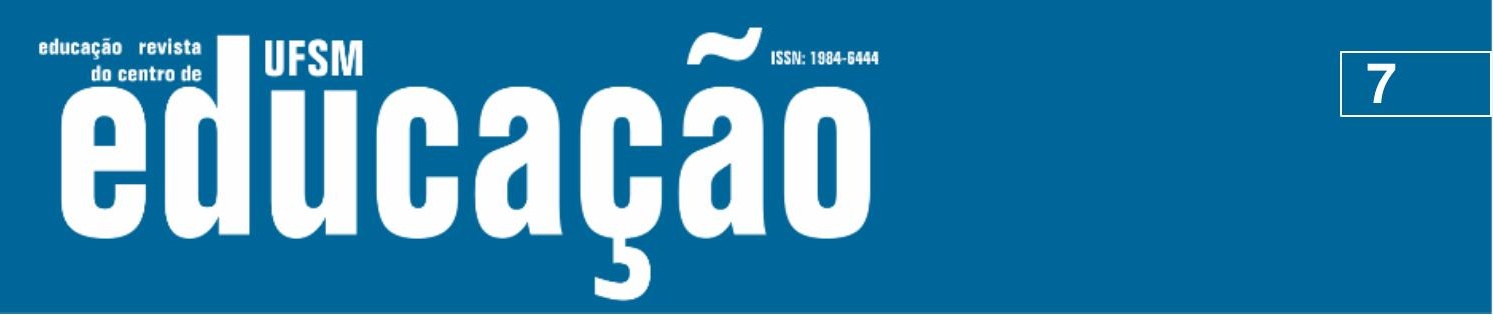

ISSN: 1984-6444 | http://dx.doi.org/10.5902/1984644461413

Na segunda metade da década de 2000, Rummert e Ventura (2007, p. 33) apontavam indícios de um duplo fenômeno: "embora vejamos ampliado o arco de ações no âmbito da EJA, o mesmo permanece centrado nas políticas focais, fragmentadas e fragmentadoras do tecido social". No entanto, "A centralidade de tais ações reside na ampliação de mecanismos de certificação, relativos à conclusão do Ensino Fundamental, à formação profissional [...] e, com menor ênfase, ao término do Ensino Médio" (RUMMERT; VENTURA, 2007, p. 34). Iniciativas que se vinculam à visão pragmática das teses neoliberais.

Uma análise mais cuidadosa revela a subsunção da quantidade à segmentação e à pulverização da oferta, expressões das fraturas, degradações e mutações modernas do mundo do trabalho, sob o signo do capitalismo neoliberal de marca neodesenvolvimentista. Para Rummert, Algebaile e Ventura (2013, p. 725),

\begin{abstract}
Uma questão central a ressaltar aqui é que quantidade e variedade não significam oferta ampla, mas sim pulverizada, desigual, irregular e instável. Isso se evidencia, entre outros aspectos, no perfil formativo dos variados programas, que pode pender para a reinserção escolar, a complementação da escolaridade, a qualificação profissional, a formação cívica ou a formação atitudinal, entre outros vieses formativos cujos sentidos verdadeiros só são apreensíveis se levarmos em conta o efeito de conjunto dessa variedade de ações instáveis e orgânicas à lógica da forte fragmentação do trabalho e do imprescindível controle social.
\end{abstract}

Desde a ascensão do ultraliberalismo, multiplicaram-se os indícios de fortalecimento das políticas de certificação, em detrimento das políticas de escolarização na Educação de Jovens e Adultos. Por exemplo, o fechamento de turmas e/ou escolas que ofertam a modalidade; a diminuição das matrículas na EJA presencial; a ampliação das matrículas na Educação a Distância no ensino médio e o revigoramento do Encceja. Um conjunto de fatos que vincula a ênfase na certificação à progressiva desresponsabilização do Estado com a escolarização presencial, abrindo espaço aos modelos mercantis que transitam da escolarização à educação não formal de jovens e adultos trabalhadores. 


\section{usm

ISSN: 1984-6444 | http://dx.doi.org/10.5902/1984644461413

\section{As matrículas na Educação de Jovens e Adultos no Ensino Médio}

Nesta seção, iremos nos debruçar sobre as matrículas de EJA/ensino médio no Brasil a partir dos dados coletados pelo Censo Escolar e sistematizados pelo INEP, no período de 2009 a 20194. É importante conhecer e interrogar esses dados, buscando compreendê-los em sua complexa historicidade, e, travando, como nos ensina Edward Thompson, "um diálogo entre o conceito e a evidência, um diálogo conduzido por hipóteses sucessivas, de um lado, e a pesquisa empírica do outro". Uma vez que, sem "engajamento empírico não há teoria" (THOMPSON, 1981, p. 49).

Confrontada com a literatura da área e com outras fontes documentais, a análise dos dados confirma a seguinte hipótese: a tendência de retração das matrículas no ensino presencial da EJA/ensino médio está vinculada à participação ativa nessa modalidade de modelos educacionais mercantis flexíveis, que transitam da escolarização à educação não formal, próprios da Educação a Distância e dos exames nacionais de certificação, demonstrando aspectos de continuidade entre os neodesenvolvimentistas e os ultraliberais.

A tabela 1 (a seguir) aborda os números anuais de matrículas na EJA/ensino médio no período de 2009 a 2014. Ao analisarmos esses números, chama-nos atenção a contínua e severa redução das matrículas - um decréscimo de quase $20 \%$ em cinco anos. Em números absolutos, significou o desaparecimento de, aproximadamente, 320 mil matriculados. 


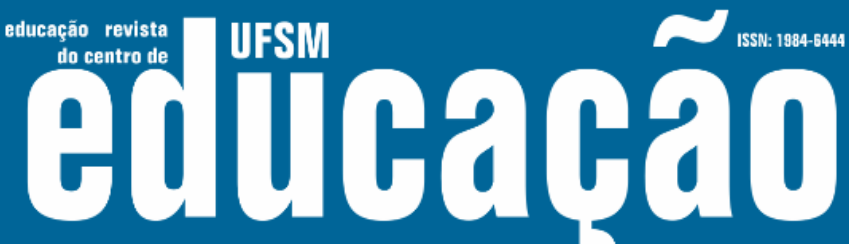 \\ 3}

ISSN: 1984-6444 | http://dx.doi.org/10.5902/1984644461413

Tabela 1 - Número de matrículas da Educação de Jovens e Adultos (EJA) no Ensino Médio por tipo de mediação didático-pedagógica e dependência administrativa, Brasil (2009-2014).

\begin{tabular}{|c|c|c|c|c|c|c|c|}
\hline \multirow{2}{*}{ Mediação } & \multirow{2}{*}{$\begin{array}{l}\text { Dependência } \\
\text { Administrativa }\end{array}$} & \multicolumn{6}{|c|}{ Ano } \\
\hline & & 2009 & 2010 & 2011 & 2012 & 2013 & 2014 \\
\hline \multirow{4}{*}{ Presencial } & Federal & 11.558 & 14.418 & 14.558 & 14.427 & 13.396 & 11.166 \\
\hline & Estadual & 1.112 .661 & 1.052.139 & 1.012 .696 & 954.348 & 956.335 & 891.522 \\
\hline & Municipal & 34.952 & 27.508 & 23.796 & 21.742 & 20.032 & 17.825 \\
\hline & Privada & 83.926 & 75.626 & 75.806 & 71.175 & 71.811 & 69.333 \\
\hline \multirow{4}{*}{$\begin{array}{l}\text { Semipre- } \\
\text { sencial }\end{array}$} & Federal & 132 & 101 & 377 & 152 & 210 & 160 \\
\hline & Estadual & 288.505 & 221.532 & 194.041 & 245.713 & 212.590 & 204.723 \\
\hline & Municipal & 18.754 & 18.270 & 19.926 & 21.305 & 20.296 & 17.849 \\
\hline & Privada & 16.320 & 17.410 & 23.193 & 17.002 & 30.208 & 34.056 \\
\hline \multicolumn{2}{|r|}{ Total } & 1.566 .808 & 1.427 .004 & 1.364 .393 & 1.345 .864 & 1.324 .878 & 1.246 .634 \\
\hline
\end{tabular}

Nota: O número de matrículas da EJA considera também as matrículas da Educação Especial em Classes Exclusivas.

Fonte: INEP - Censo Escolar da Educação Básica, 2009-2014.

Uma observação mais detalhada da tabela 1 aponta outros dados que contribuem para explicar alguns aspectos dessa redução de matrículas. O mais evidente é a severa redução na dependência administrativa estadual. As suas duas mediações didático-pedagógicas somadas, presencial e semipresencial, respondem por cerca de 305 mil das 320 mil matrículas perdidas no total, o que significa em torno de $95 \%$ da redução do período.

Cabe esclarecer que o termo mediação didático-pedagógica é cunhado pelo INEP para referir-se a presencial, semipresencial e a distância, desde o Censo Escolar de 2015, quando passou a identificar as turmas nestas três categorias: mediação didático-pedagógica presencial, semipresencial e a distância ${ }^{5}$.

As perdas não se limitaram exclusivamente a uma das mediações; entretanto, elas foram mais acentuadas na mediação presencial. Isso fica evidente ao considerarmos que a semipresencial, que se expandiu nas outras dependências administrativas, teve na dependência Estadual uma redução acima de 80 mil matrículas, aproximadamente, $29 \%$ das perdas gerais do período. Enquanto na 


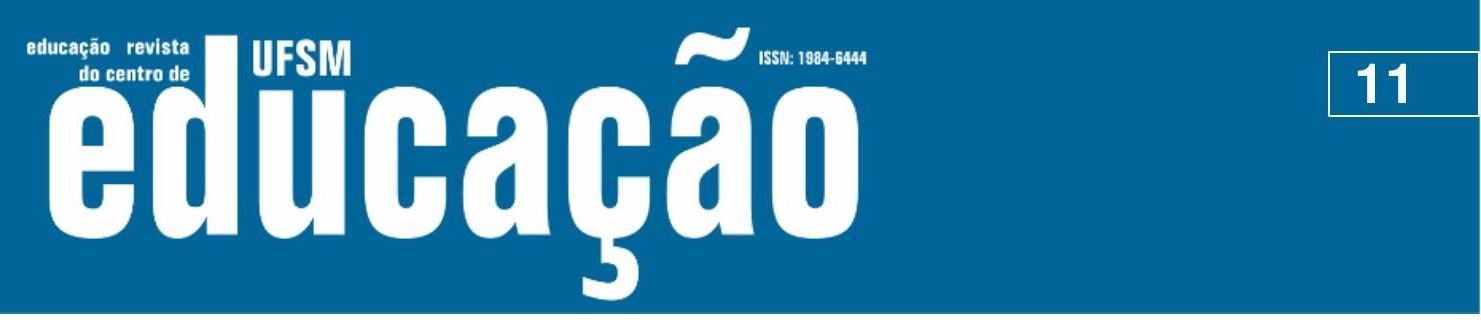

ISSN: 1984-6444 | http://dx.doi.org/10.5902/1984644461413

Essa trajetória descendente das matrículas na EJA/ensino médio não pode ser creditada à instabilidade econômica. As ações governamentais anticíclicas responderam bem à forte crise de 2008. Também não é possível recorrer à instabilidade política. O Presidente da República gozava de altíssima popularidade e elegeu a sua sucessora em 2010; nada menos do que 13 governadores se reelegeram (ARAÚJO; TAVARES; BARBOSA, 2012), e nas eleições municipais de 2012, 14 das 26 capitais e 20 das 33 cidades com mais de 200 mil habitantes elegeram prefeitos de partidos da coalização que sustentava o Governo Federal, além de o partido que a liderava vencer em São Paulo (D'AGOSTINO, 2012). Tampouco podemos atribuir o recuo à instabilidade social. O Governo Federal dispunha de programas sociais para atender os mais vulneráveis. Por exemplo, o Programa Bolsa Família atendia, em 2011, a 13,352 milhões famílias, ao custo $\mathrm{R} \$ 16,699$ bilhões (CARDOSO, 2011). A "questão social" estava sob relativo controle desde meados da década anterior, quando o Governo Federal criou programas de transferência de renda.

Assim, não nos parece que a aguda queda das matrículas na EJA/ensino médio possa ser associada a qualquer tipo de instabilidade. A redução continuada das matrículas expressa os princípios norteadores e as prioridades das políticas de Estado, que beneficiam uns grupos em detrimento de outros. Não é por acaso que as ações governamentais passaram a incentivar a certificação via o Exame Nacional do Ensino Médio (Enem) ${ }^{7}$. Também não foi acidental a ênfase do setor privado na mediação semipresencial. Pretendia ocupar nichos de mercado deixados pelo Estado $^{8}$, e ter preços suficientemente competitivos para minimizar as perdas de matrículas presenciais e atrair aqueles estimulados pela promessa de certificação via Enem.

A tabela 2 (abaixo) apresenta os números anuais de matrículas na EJA/ensino médio no período de 2015 a 2019. A observação da segunda tabela evidencia a interrupção da tendência de queda no número de matrículas. Se compararmos 2018, ano do auge de matrículas dessa lenta recuperação, ainda se percebe um déficit de quase 130 mil matrículas, 8\% inferior ao ano de $2009^{9}$. Com a interrupção da expansão em 2019 , com queda relativa de $7 \%$ de matrículas em comparação ao ano 


\section{تีtînaคẫ \\ 3}

ISSN: 1984-6444 | http://dx.doi.org/10.5902/1984644461413

de 2018, os números retornaram um patamar muito próximo das matrículas de 2015, fragilizando sensivelmente a recuperação dos anos anteriores ${ }^{10}$.

Tabela 2 - Número de matrículas da Educação de Jovens e Adultos (EJA) no Ensino Médio por tipo de mediação didático-pedagógica e dependência administrativa, Brasil (2015-2019).

\begin{tabular}{|c|c|c|c|c|c|c|}
\hline \multirow{2}{*}{ Mediação } & \multirow{2}{*}{$\begin{array}{l}\text { Dependência } \\
\text { Administrativa }\end{array}$} & \multicolumn{5}{|c|}{ Ano } \\
\hline & & 2015 & 2016 & 2017 & 2018 & 2019 \\
\hline \multirow{4}{*}{ EaD } & Federal & 608 & 216 & 216 & -- & 13 \\
\hline & Estadual & 1.291 & 2.647 & 1.798 & 1.586 & 1.665 \\
\hline & Municipal & 53 & -- & 74 & -- & -- \\
\hline & Privada & 54.728 & 40.927 & 54.638 & 62.956 & 66.870 \\
\hline \multirow{4}{*}{ Presencial } & Federal & 10.541 & 10.872 & 11.777 & 12.226 & 13.579 \\
\hline & Estadual & 911.775 & 995.673 & 1.040 .108 & 1.055 .235 & 963.604 \\
\hline & Municipal & 17.036 & 15.661 & 15.338 & 12.407 & 9.728 \\
\hline & Privada & 62.864 & 48.127 & 44.716 & 40.670 & 35.059 \\
\hline \multirow{4}{*}{$\begin{array}{l}\text { Semipre- } \\
\text { sencial }\end{array}$} & Federal & 16 & -- & -- & 30 & 35 \\
\hline & Estadual & 205.867 & 217.194 & 205.715 & 202.952 & 199.637 \\
\hline & Municipal & 16.578 & 19.561 & 20.804 & 19.612 & 18.968 \\
\hline & Privada & 26.043 & 25.761 & 30.628 & 30.159 & 26.927 \\
\hline \multicolumn{2}{|c|}{ Total } & 1.307 .400 & 1.376 .639 & 1.425 .812 & 1.437 .833 & 1.336 .085 \\
\hline
\end{tabular}

Nota: O número de matrículas da EJA considera também as matrículas da Educação Especial em Classes Exclusivas.

Fonte: INEP - Censo Escolar da Educação Básica, 2015-2019.

De todo modo, a breve recuperação no período de 2015 a 2018 parece ser resultado de alterações na forma de efetivar políticas públicas para a modalidade. Em 2019, Carlos Eduardo Moreno Sampaio, diretor de Estatísticas Educacionais do Inep, ao tratar da tendência de queda de matrículas no ensino médio nos últimos anos, avaliou que, além dos componentes demográficos e da melhoria no fluxo no ensino médio, a "queda também pode ser explicada pelas altas taxas de evasão e da migração de alunos para a Educação de Jovens e Adultos (EJA)" (BRASIL, 2019b, grifo nosso $)^{11}$. Parece-nos que essas políticas incentivavam a migração do regular para a EJA. 


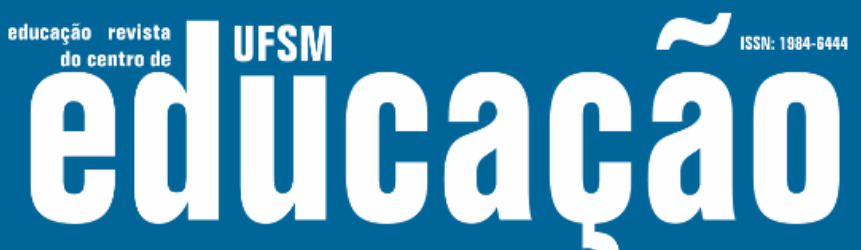

ISSN: 1984-6444 | http://dx.doi.org/10.5902/1984644461413

EJA/ensino médio por meio da EaD teve 68.548 matriculados; destes, nada menos do que 66.870 estavam na rede privada, mais de $97 \%$ das matrículas.

Se a análise da tabela 2 nos permitiu perceber que a EaD continua ampliando os seus números, mesmo diante de um recuo das matrículas totais da EJA/ensino médio no ano de 2019, também tornou visível a dificuldade da mediação presencial da dependência administrativa estadual voltar a crescer acima do patamar de 11 anos atrás. Há uma década, a mediação presencial na dependência estadual permanece presa a uma faixa de variação entre 0,9 e 1,05 milhão de matrículas na EJA/ensino médio.

Os números do início da série, acima de 1,1 milhão de matriculados, nunca foram ultrapassados; o mais próximo que se chegou dessa quantidade foi em 2018, dez anos depois, com 1,05 milhão de matriculados no presencial, quase 60 mil matrículas a menos que o pico de 2009. Mas, já no ano seguinte, os números voltaram a um patamar inferior a um milhão, compatíveis com a média dos últimos 11 anos, que é de 995.1 mil matrículas ao ano.

Embora a observação da tabela 2 aponte para o crescimento contínuo das matrículas na mediação presencial da dependência administrativa estadual de 2015 a 2018, apenas os números dos anos 2017 e 2018 superaram a média histórica dos últimos 11 anos - e foram logo sucedidos por uma queda a um patamar inferior, em 2019. Desse modo, a análise da Tabela 2, ao confirmar o fracasso do Estado Brasileiro em retomar os patamares de matrículas de uma década atrás, chama atenção para a negligência dos governos estaduais na condução de ações efetivas para garantir a escolarização EJA/ensino médio.

A Figura 1 apresenta o número de matrículas da EJA no ensino médio por mediação didático-pedagógica no Brasil, de 2009 a 2019. Ao observá-la, percebemos a noção do movimento descendente geral das matrículas no período e, ao mesmo tempo, a precisão das oscilações de cada uma das três mediações didáticopedagógicas: 


\section{تilfoarẫ \\ (3)}

ISSN: 1984-6444 | http://dx.doi.org/10.5902/1984644461413

Figura 1 - Gráfico de matrículas da EJA.

Número de matrículas da EJA no Ensino Médio por mediação didático pedagógica Brasil, 2009-2019

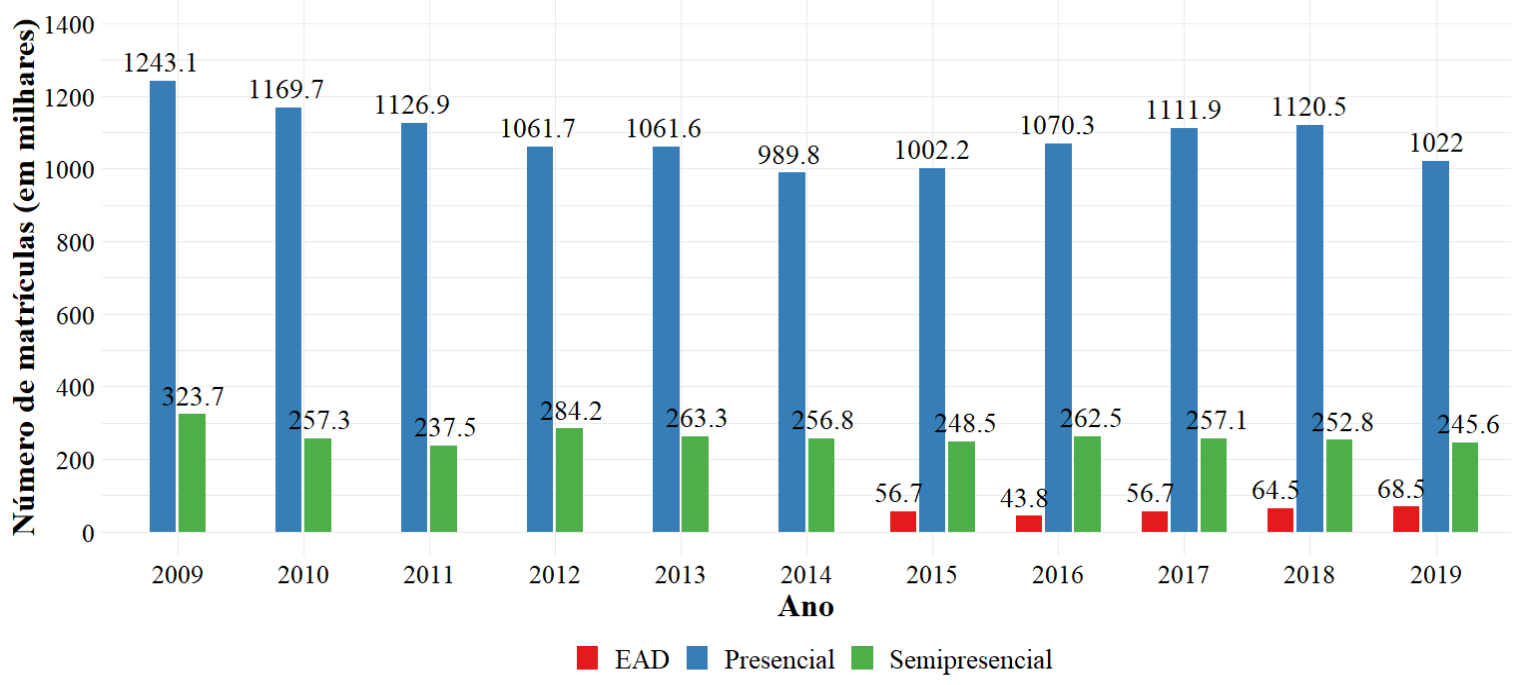

Fonte: INEP - Censo da Educação Básica, 2009-2019.

Uma análise mais detida da Figura nos permite compreendê-la como síntese visual da incapacidade do Estado Brasileiro e de seus entes federados de garantir aos jovens e adultos trabalhadores o acesso à escolarização média. A observação em conjunto das Tabelas e da Figura confirma a tendência longitudinal de redução das matrículas na EJA/ensino médio. O país, ao não superar os números de matrículas de uma década atrás, evidencia o longo "compasso de espera" a que está submetida à oferta nessa etapa da modalidade; em particular, nos governos estaduais que, por dispositivo legal, concentram a maior parte das matrículas na EJA/ensino médio.

Uma realidade duradoura e arraigada que não pode ser compreendida pelas eventualidades da conjuntura. Portanto, é preciso, também, associá-la aos eixos que, nesses onze anos, orientaram as políticas públicas para a Educação de Jovens e Adultos no Estado Brasileiro e nos seus entes federados.

Historicamente, as políticas públicas para a escolarização na EJA nunca foram muito além do foco nas pessoas que ativamente demandam a educação formal. Estruturar as ações prioritariamente naqueles que demandam a EJA submete essas políticas educacionais a toda sorte de eventualidades conjunturais que afeta a 


\section{تutดaดูão}

ISSN: 1984-6444 | http://dx.doi.org/10.5902/1984644461413

sociedade, e que vão, por exemplo, desde problemas com a localização da escola até a precarização do mercado de trabalho.

Essa passividade do Estado transfere aos estudantes, que ocupam, em geral, as posições mais vulneráveis na hierarquia social, a responsabilidade pela manutenção da própria ação educacional. Portanto, apostar apenas na demanda real naturaliza as dificuldades sociais e específicas dos estudantes, e desconhece e/ou desconsidera as enormes barreiras que precisam ser superadas cotidianamente para o estudante chegar e se manter na sala de aula.

As políticas educacionais para a EJA/ensino médio, nos últimos 11 anos, com raras exceções, alicerçaram-se nesse pressuposto. Os gestores mantiveram o interesse real imediato do jovem e do adulto como eixo organizador das ações nessa etapa da modalidade. Obviamente, os impedimentos e as interdições históricas foram reproduzidos. Em 2013, na entrevista intitulada "Os governos desistiram da EJA", dada à revista eletrônica Gestão Escolar, Sérgio Haddad, analisando a queda acentuada das matrículas, afirma, corroborando conosco:

São muitas as barreiras que precisam ser superadas para a EJA dar certo. [...] O aluno mal sabe onde há vaga. Não se investe em divulgação, que precisaria ser feita nos metrôs, nos ônibus e pela internet. Além disso, o público da EJA raramente toma a iniciativa de procurar a escola, por vergonha ou por acreditar que o tempo de estudar passou. Teria de haver uma atitude ativa do Estado e uma intensa mobilização. (HADDAD, 2013)

Nesse sentido, centralizar as políticas públicas para a EJA/ensino médio apenas na demanda ativa, naqueles que, superando todos os desafios, procuram a escola, é uma das dimensões que contribuem para a tendência de redução continuada das matrículas nessa etapa dessa modalidade. Essa postura precisa ser substituída por uma política indutora e proativa do Estado; medida importante para superar a tendência regressiva das matrículas na EJA na etapa final da Educação Básica. Infelizmente não foi isso que vimos nos primeiros anos da década de 2010, dominados politicamente pela ideologia neodesenvolvimentista, e, muito menos depois, sob os auspícios políticos do ultraliberalismo.

Se a passividade das políticas públicas para a escolarização na EJA foi um dos eixos que contribuiu para a tendência de redução de matrículas que dominou a década 


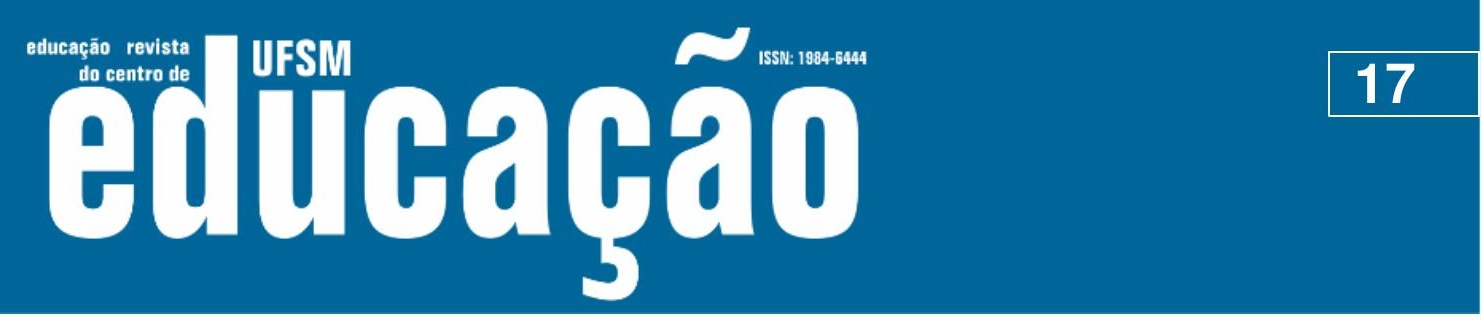

ISSN: 1984-6444 | http://dx.doi.org/10.5902/1984644461413

de 2010, a forma como as mediações didático-pedagógicas foi politicamente organizada também cooperou para esse fim. Tradicionalmente alternativa à mediação presencial, a Educação a Distância semipresencial ganhou o reforço de uma EaD, executada totalmente em Ambiente Virtual de Aprendizagem (AVA) através das Tecnologias de Informação e Comunicação (TICs). Embora ricas em potencialidades - experiências com vasto repertório de possibilidades, com mediadores que vão do professor à inteligência artificial -, elas têm sido usadas como substitutas, precarizadas e baratas, da escolarização presencial.

Durante toda a década de 2010, na EJA/ensino médio nas redes públicas estaduais, as matrículas semipresenciais corresponderam a, aproximadamente, um quinto das presenciais e permaneceram nesse patamar durante todo o período. No entanto, os municípios e, principalmente, o setor privado substituíram as matrículas presenciais pelas matrículas semipresenciais; nesse último, de 2009 a 2014, as matrículas semipresenciais mais que dobraram, enquanto as presenciais reduziramse significativamente, mostram os dados do Censo Escolar (ver Tabela 1).

A partir de 2015, com a contabilização independente das matrículas EJA/ensino médio na $\mathrm{EaD}$, verificou-se tanto o controle do setor privado sobre essa mediação quanto o uso dela em substituição das matrículas presenciais. A legislação de 2017, ratificada pelo Conselho Nacional de Educação (CNE), aponta para a ampliação do uso da EaD na EJA/ensino médio e para a consolidação do controle empresarial nessa mediação.

As políticas públicas para a EJA no ensino médio na última década, de um modo geral, não garantiram atenção adequada à escolarização presencial e, ao mesmo tempo, incentivaram outras mediações didático-pedagógicas, em especial a EaD. Por caminhos semelhantes, mas não idênticos, neodesenvolvimentistas e ultraliberais distanciaram-se da escolarização presencial na EJA/ensino médio e estreitaram as relações da modalidade com o empresariado.

Os neodesenvolvimentistas incentivaram a iniciativa privada a assumir a execução de serviços públicos considerados não essenciais com o objetivo de fortalecê-la e, simultaneamente, desresponsabilizar o Estado por esses serviços. Favoreceram parcerias com instituições privadas e públicas - com os estados, o 


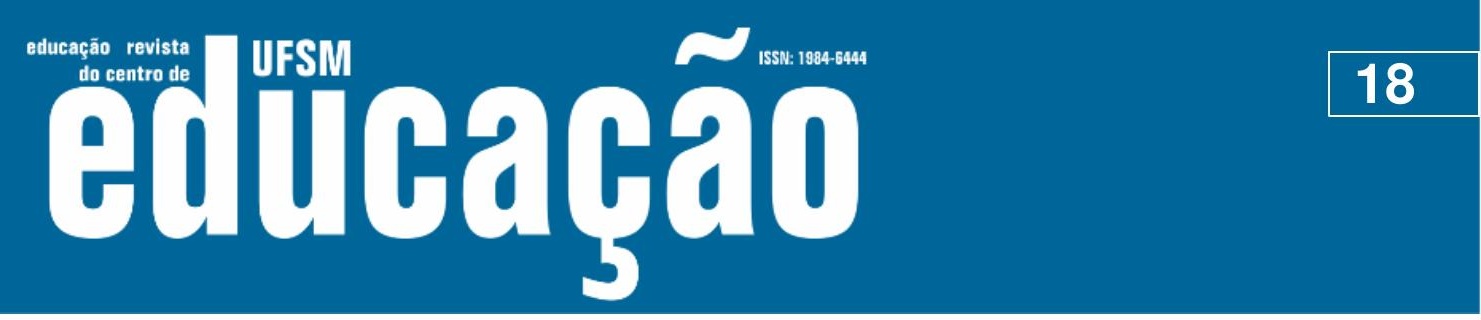

ISSN: 1984-6444 | http://dx.doi.org/10.5902/1984644461413

Sistema $S$ e as universidades privadas $^{15}$ - financiando, por adesão, ações previamente desenhadas que, entre outros, atingia o público em potencial da EJA/ensino médio ${ }^{16}$. Ao mesmo tempo, criou as condições para a atuação da EaD nessa etapa da modalidade e incentivou, via Enem, a certificação do ensino médio.

Já os ultraliberais, no mesmo ano em que ascenderam ao poder, reformaram o ensino médio ${ }^{17}$, e com ele a EJA nessa etapa ${ }^{18}$; revitalizaram o Encceja, e, através de legislação, fortaleceram a presença da $\mathrm{EaD}^{19}$. Embora os neodesenvolvimentistas tenham feito críticas à reforma do ensino médio, no que se refere à EJA nessa etapa, os primeiros aprofundam as ações dos segundos, portanto, há a continuidade e não o rompimento entre as duas variações do neoliberalismo. Ambas fortalecem a desresponsabilização dos Estados e, em particular, do governo federal, com a modalidade na mediação presencial no ensino médio, através da abertura para a participação da EaD e do empresariado da educação na EJA.

Portanto, as políticas públicas para a EJA de ambos mantiveram a tendência de retração das matrículas na mediação presencial da EJA/ensino médio e incentivaram a adoção na modalidade de modelos educacionais mercantis flexíveis, que transitam da escolarização à educação não formal, próprios da Educação a Distância.

Outro eixo que acompanha as políticas para a EJA neste século é a certificação. Em 2002, no fim do segundo Governo Cardoso, foi criado o Exame Nacional para Certificação de Competências de Jovens e Adultos (ENCCEJA), pela Portaria no 2.270/2002 do Ministério da Educação (BRASIL, 2002).

Os exames de certificação em massa, nos últimos 11 anos, passaram a ser parte orgânica das políticas para a EJA/ensino médio. Primeiro, através do Enem, que, reformulado em 2009, tornou-se certificatório para o ensino médio (BRASIL, 2009) forma de burlar as críticas ao ENCCEJA, que o governo desejava ressuscitar. No entanto, em função de resultados pouco produtivos, em 2016, o Enem foi abandonado como certificação para o ensino médio; mas, com o novo governo, de orientação ultraliberal, a ideia de certificação em massa ganhou força. Ele valorizou e incentivou a realização do Encceja $^{20}$, enquanto criava condições legais para que a EJA/ensino médio pudesse ter a maior parte de sua carga horária à distância, adequando-a para 


\section{Authaดูã}

ISSN: 1984-6444 | http://dx.doi.org/10.5902/1984644461413

consumir serviços educacionais voltados ao aligeiramento da presença do estudante na escola.

Os dados nos permitem acreditar que estamos diante de uma estratégia, que domina todo este quinto de século, de privilegiar o incentivo à certificação como política de Estado para a EJA/ensino médio. Seja por meios como o Enem e o Encceja, ou pelas restrições que a $\mathrm{EaD}$ impõe à EJA presencial, ou por tudo isso junto, fato é que o neodesenvolvimentismo não produziu políticas de educação para jovens e adultos trabalhadores para além dos limites do ideário neoliberal.

Em 2011, Ventura já criticava alguns aspectos da perspectiva "ser educado é ser certificado" (VENTURA, 2011, p. 83), que acompanhavam o conjunto dos programas que contornavam a escolarização na EJA. Ao chegar ao poder, o ultraliberalismo levou ao extremo os elementos que estavam postos pelos seus antecessores. Portanto, ambos, em intensidades diferentes, contribuíram para esvaziar o direito de jovens e adultos à escolarização. E, também, para estreitar os vínculos do estudante da EJA com a educação não presencial e, em sentido amplo, com a educação não formal e com o mercado de certificação.

\section{Considerações finais}

Neste texto, analisamos os dados quantitativos nacionais sobre as matrículas na Educação de Jovens e Adultos no ensino médio ao longo dos anos 2010, correlacionando-os com as ações educacionais do neodesenvolvimentismo e do ultraliberalismo no cenário mais amplo da redemocratização de orientação neoliberal no Brasil.

Com o objetivo de compreender a tendência de retração das matrículas na EJA/ensino médio na última década, refletimos sobre alguns eixos que guiaram as políticas públicas para a EJA nessa etapa de ensino: a forma de lidar com a demanda; a relação da flexibilização das mediações didático-pedagógicas com o mercado; e a certificação em massa. Em seguida, relacionamos esses eixos com as políticas públicas para a EJA/ensino médio neodesenvolvimentistas e ultraliberais. 


\section{$\sim$ Eutoabga}

ISSN: 1984-6444 | http://dx.doi.org/10.5902/1984644461413

As bases da ideologia neoliberal, hegemônica na sociedade brasileira desde o início dos anos 1990, com uma nova roupagem, continuaram orientando as políticas educacionais no Brasil neodesenvolvimentista. As iniciativas na educação escolar de nível médio para jovens e adultos trabalhadores, embora envolvendo a ampliação de investimentos para todos os entes da federação, materializaram-se, segundo os dados do Censo Escolar, em redução continuada do número de matrículas no ensino médio nessa modalidade, o que está visível na Tabela 1.

A intricada e complexa crise do projeto neodesenvolvimentista levou à sua queda e à ascensão dos ultraliberais. Estes, no poder, foram incapazes de unir as diferentes frações das classes dominantes e reorganizar a hegemonia neoliberal no país: a crise continua há cinco anos ininterruptos.

Em meio à crise, as ações ultraliberais pouco se importaram em recuperar sustentadamente os números de matrículas na EJA/ensino médio, algumas delas continuadas da gestão anterior. As já elaboradas sob a égide ultraliberal, como a reforma do ensino médio, foram profundamente criticadas. A começar por ter sido conduzida via Medida Provisória, o que excluiu o debate mais aprofundado sobre a temática. $\mathrm{O}$ fato é que os números continuaram aquém de 10 anos atrás.

Nesse sentido, há nítidos aspectos de continuidade nas políticas públicas para a EJA/ensino médio entre os neodesenvolvimentistas e os ultraliberais. Elas vinculam a modalidade a modelos educacionais mercantis flexíveis, que transitam da escolarização à educação não formal, próprios da Educação a Distância e dos exames de certificação. O neodesenvolvimentismo submergiu às teses neoliberais, das quais o ultraliberalismo é um defensor intransigente. Assim, os primeiros são uma versão enfraquecida dos segundos. Segundo Tácito, historiador na Roma antiga, "A marca do escravo é falar a língua dos seus amos".

\section{Referências}

ARAÚJO, Cacau; TAVARES, Eduardo; BARBOSA, Vanessa. Os governadores eleitos nas eleições de 2010. Exame, [S.I.], 23 ago. 2012. Disponível em: https://exame.com/brasil/conheca-os-27-governadores-eleitos. Acesso em: 9 jun. 2020. 


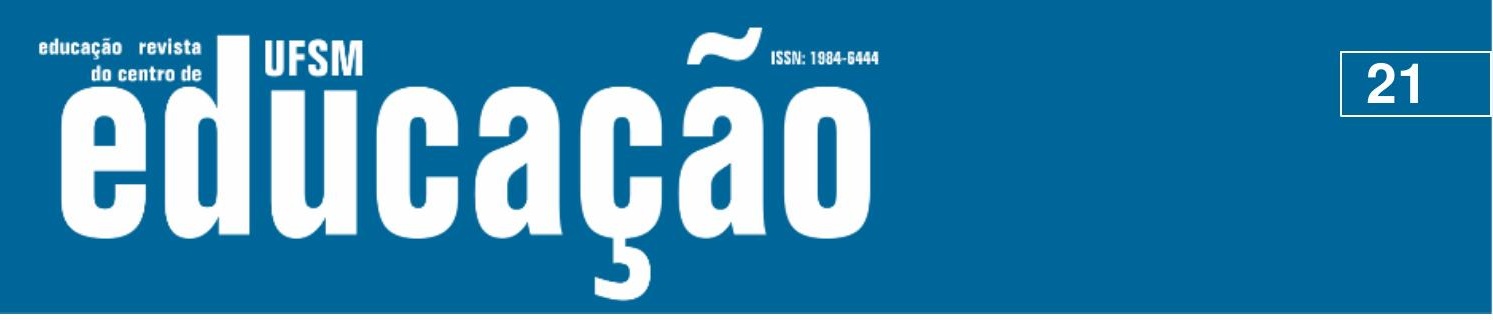

ISSN: 1984-6444 | http://dx.doi.org/10.5902/1984644461413

BOITO JÚNIOR, Armando. A crise política do neodesenvolvimentismo e a instabilidade da democracia. Crítica Marxista, São Paulo, n. 42, p. 155-162, 13 abr. 2016.

Disponível

em:

https://www.ifch.unicamp.br/criticamarxista/arquivos_biblioteca/dossie2017_03_03_1 0_57_34.pdf. Acesso em: 9 jun. 2020.

BOITO JÚNIOR, Armando; BERRINGER, Tatiana. Brasil: classes sociais, neodesenvolvimentismo e política externa nos governos Lula e Dilma. Revista de Sociologia e Política, Curitiba, v. 21, n. 47, p. 31-38, set. 2013. https://doi.org/10.1590/S0104-44782013000300004.

BRASIL. Decreto no 9.057, de 25 de maio de 2017. Brasília, DF, 2017a. Disponível em: http://www.planalto.gov.br/ccivil_03/_ato2015-2018/2017/decreto/d9057.htm. Acesso em: 10 jun. 2020.

BRASIL. Instituto Nacional de Estudos e Pesquisas Educacionais Anísio Teixeira. Caderno de Conceitos e Orientações do Censo Escolar 2019 - Matrícula Inicial. Brasília, DF, 2019a. Disponível em: http://download.inep.gov.br/educacao_basica/educacenso/situacao_aluno/document os/2019/caderno_de_conceitos_e_orientacoes_censo_escolar2019_versao_final.pdf . Acesso em: 9 jun. 2020.

BRASIL. Instituto Nacional de Estudos e Pesquisas Educacionais Anísio Teixeira. Censo Escolar 2018. Brasília, DF, 2018a. Disponível em: http://download.inep.gov.br/educacao_basica/censo_escolar/apresentacao/2019/apr esentacao_coletiva_censo_escolar_2018.pdf. Acesso em: 12 jun. 2020.

BRASIL. Instituto Nacional de Estudos e Pesquisas Educacionais Anísio Teixeira. Censo Escolar 2018 revela crescimento de 18\% nas matrículas em tempo integral no ensino médio. Brasília: INEP, 2019b. Disponível em: http://portal.inep.gov.br/artigo/-/asset_publisher/B4AQV9zFY7Bv/content/censoescolar-2018-revela-crescimento-de-18-nas-matriculas-em-tempo-integral-no-ensinomedio/21206. Acesso em: 12 jun. 2020.

BRASIL. Instituto Nacional de Estudos e Pesquisas Educacionais Anísio Teixeira. Matrículas em creches públicas crescem em 2019; Ensino Médio em tempo integral também registra crescimento. Brasília: INEP, 2020. Disponível em: http://portal.inep.gov.br/artigo2/-

/asset_publisher/GngVoM7TApe5/content/matriculas-em-creches-publicas-crescemem-2019-ensino-medio-em-tempo-integral-tambem-registracrescimento/21206.Acesso em: 12 jun. 2020.

BRASIL. Instituto Nacional de Estudos e Pesquisas Educacionais Anísio Teixeira. Portaria no 109, de 27 de maio de 2009. Brasília, DF, 2009. Disponível em: http://download.inep.gov.br/educacao_basica/enem/legislacao/2009/portaria_enem_ 2009_1.pdf. Acesso em: 10 jun. 2020. 


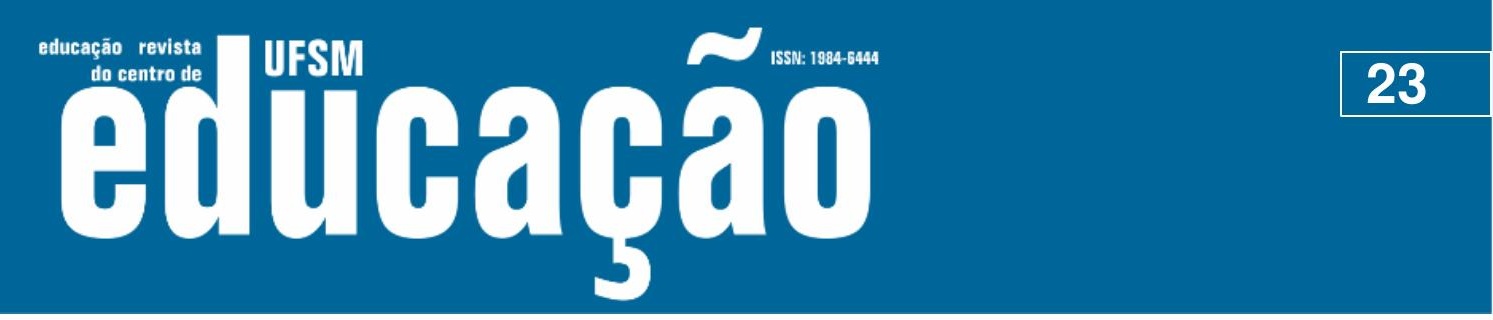

ISSN: 1984-6444 | http://dx.doi.org/10.5902/1984644461413

HADDAD, Sérgio. "Os governos desistiram da EJA". [Entrevista concedida a] Elisângela Fernandes. Nova Escola, [S.I.], 1 set. 2013. Disponível em: https://novaescola.org.br/conteudo/7834/os-governos-desistiram-da-eja. Acesso em: 10 jun. 2020.

HADDAD, Sérgio; XIMENES, Salomão Barros. A educação de pessoas jovens e adultas e a nova LDB: um olhar passados 17 anos. In: BRZEZINSKI, Iria (Org.). LDB/1996 Contemporânea: contradições, tensões, compromissos. São Paulo: Cortez Editora, 2014. p. 233-255.

LEHER, Roberto. 'Que modelo de 'inclusão social' nós vamos ter com essas escolas?'. [Entrevista concedida a] Cátia Guimarães. Escola Politécnica de Saúde Joaquim Venâncio/Fiocruz, Rio de Janeiro, 2011. Disponível em: http://www.epsjv.fiocruz.br/noticias/entrevista/que-modelo-de-inclusao-social-nosvamos-ter-com-essas-escolas. Acesso em: 29 ago. 2019.

MACHADO, Maria Margarida. Educação de Jovens e Adultos - Após 20 vinte anos da Lei no 9.394, de 1996. Revista Retratos da Escola, Brasília, v. 10, n. 19, p. 429-451, jul./dez. $2016 . \quad$ Disponível em: http://retratosdaescola.emnuvens.com.br/rde/article/view/687. Acesso em: 9 jun. 2020.

MACHADO, Maria Margarida; RODRIGUES, Maria Emília de Castro. Educação de Jovens e Adultos - Relação Educação e Trabalho. Revista Retratos da Escola, Brasília, v. 7, n. 13, p. 373-385, jul./dez. 2013. Disponível em: http://retratosdaescola.emnuvens.com.br/rde/article/view/312. Acesso em: 9 jun. 2020.

MORENO, Ana Carolina. Aprovação aumenta após prova do Encceja substituir a do Enem para quem busca 'diploma' do ensino médio. G1, [S.I.], 6 abr. 2019. Disponível em: https://g1.globo.com/educacao/noticia/2019/04/06/aprovacao-aumenta-aposprova-do-encceja-substituir-a-do-enem-para-quem-busca-diploma-do-ensinomedio.ghtml. Acesso em: 10 jun. 2020.

NEVES, Lúcia Maria Wanderley. As reformas da educação escolar brasileira e a formação de um intelectual urbano de novo tipo. In: REUNIÃO ANUAL DA ASSOCIAÇÃO NACIONAL DE PESQUISA E PÓS-GRADUAÇÃO EM EDUCAÇÃO, 27., 2004, Caxambu. Programas e resumos. Caxambu, MG: ANPEd, 2004. Disponível em: http://www.anped.org.br/sites/default/files/t0510.pdf. Acesso em: 9 jun. 2020.

PALHARES, Isabela. Alunos do fundamental já migram mais para EJA do que os do ensino médio. Estadão, São Paulo, 21 jun. 2017. Disponível em: https://educacao.estadao.com.br/noticias/geral,alunos-do-fundamental-ja-migrammais-para-eja-do-que-os-do-ensino-medio,70001852246. Acesso em: 12 jun. 2020. 


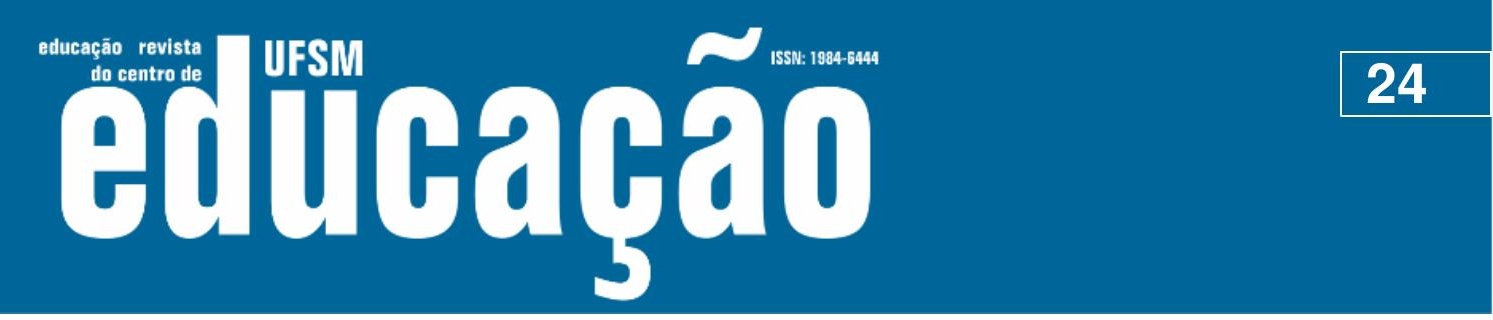

ISSN: 1984-6444 | http://dx.doi.org/10.5902/1984644461413

RUMMERT, Sonia Maria; ALGEBAILE, Eveline; VENTURA, Jaqueline. Educação da classe trabalhadora brasileira: expressão do desenvolvimento desigual e combinado. Revista Brasileira de Educação, Rio de Janeiro, v. 18, n. 54, p. 717-738, jul./set. 2013. https://doi.org/10.1590/S1413-24782013000300011.

RUMMERT, Sonia Maria; VENTURA, Jaqueline Pereira. Políticas públicas para educação de jovens e adultos no Brasil: a permanente (re)construção da subalternidade - considerações sobre os Programas Brasil Alfabetizado e Fazendo Escola. Educar em Revista, Curitiba, n. 29, p. 29-45, jan./jun. 2007. https://doi.org/10.1590/S0104-40602007000100004.

SAVIANI, Dermeval. Políticas educacionais em tempos de golpe. [Entrevista concedida a] Jorge Fernando Hermida e Jailton de Souza Lira. Educação e Sociedade, Campinas, v. 39, n. 144, set. 2018. http://dx.doi.org/10.1590/es010173302018190268.

TODOS PELA EDUCAÇÃO. Anuário Brasileiro da Educação Básica 2019. São Paulo: Editora $\quad 2019 . \quad$ Doderna, Disponível em: https://www.todospelaeducacao.org.br/_uploads/_posts/302.pdf. Acesso em: 10 jun. 2020.

THOMPSON, E. P. A miséria da teoria. Rio de Janeiro: Zahar, 1981.

VENTURA, Jaqueline Pereira. A trajetória histórica da educação de jovens e adultos trabalhadores. In: TIRIBA, Lia; CIAVATTA, Maria (Org.). Trabalho e Educação de Jovens e Adultos. Brasília: Liber Livro; Niterói: EdUFF, 2011. p. 57-97.

VENTURA, Jaqueline Pereira. Educação de jovens e adultos ou educação da classe trabalhadora? Concepções em disputa na contemporaneidade brasileira. 2008. Tese (Doutorado em Educação) - Universidade Federal Fluminense, Niterói, 2008.

\section{(@) $(1) \Theta$}

This work is licensed under a Creative Commons Attribution-NonCommercial 4.0 International (CC BY-NC 4.0)

\section{Notas}

\footnotetext{
${ }^{1}$ Considerar os sujeitos da EJA como trabalhadores não ignora ou nega que as classes são compostas por grupos sociais específicos.

${ }^{2} \mathrm{O}$ uso da expressão Educação a Distância não significa adesão acrítica a esse termo. É usada para não dificultar a compreensão textual, já que é uma expressão de uso corrente dos empresários da educação, das secretarias de educação e do próprio MEC.
} 


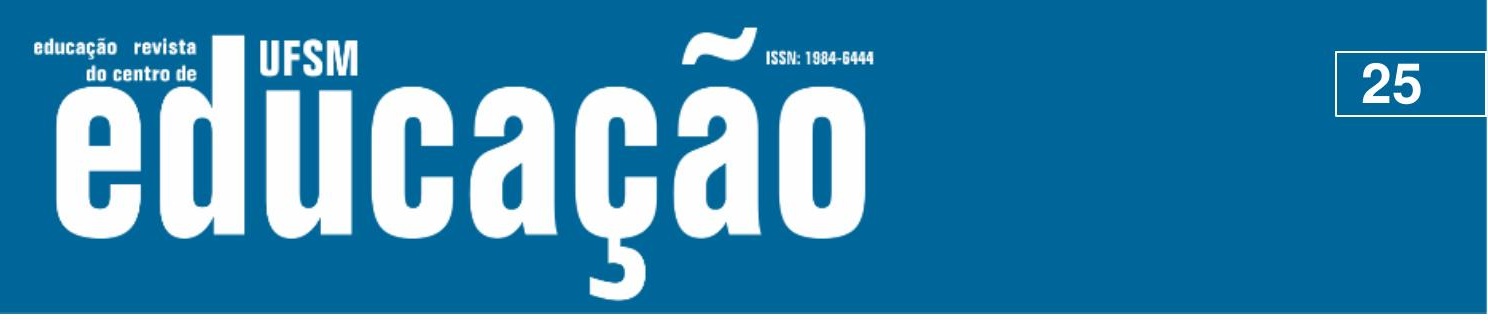

ISSN: 1984-6444 | http://dx.doi.org/10.5902/1984644461413

\begin{abstract}
${ }^{3}$ Essa massa, social e politicamente desorganizada, “[...] foi incluída na frente neodesenvolvimentista graças às políticas de transferência de renda dos governos Lula da Silva e Dilma Rousseff. O programa Bolsa Família, destinado às famílias que se encontram abaixo da linha de pobreza, e o chamado Benefício de Prestação Continuada, destinado a idosos e a pessoas com deficiência, são os principais instrumentos dessa política" (BOITO JÚNIOR; BERRINGER, 2013, p. 34, grifos dos autores).
\end{abstract}

${ }^{4} \mathrm{O}$ recorte temporal justifica-se por corresponder ao auge e à crise do neodesenvolvimentismo e à ascensão do ultraliberalismo.

${ }^{5}$ A partir de 2015, o Censo Escolar realizado pelo INEP passou a identificar as turmas por três categorias chamadas de mediação didático-pedagógica: presencial, semipresencial e a distância $(\mathrm{EaD})$ e as definiu assim: "Presencial Turma de curso realizado presencialmente com alunos e professores desenvolvendo atividades educativas no mesmo lugar e ao mesmo tempo, com frequência mínima obrigatória. Semipresencial Turma de curso realizado com atividades, módulos ou unidades de ensino-aprendizagem centrados na autoaprendizagem, com a mediação de recursos didáticos organizados em diferentes suportes de informação e avaliações presenciais. A distância (EaD) Turma de curso cuja mediação didático-pedagógica dos processos de ensino-aprendizagem ocorra com a utilização de meios e tecnologias de informação e comunicação (TIC), com pessoal qualificado, com políticas de acesso, com acompanhamento e avaliação compatíveis, entre outros. As atividades educativas são desenvolvidas por alunos e profissionais da educação que estão em lugares ou tempos diversos" (BRASIL, 2019a, p. 45).

${ }^{6}$ Chamam atenção números tão pífios de matrículas. Machado e Rodrigues (2013) afirmam que, pela invisibilidade numérica, o Proeja não impactou a rede federal e nem a política nacional. Sobre essa questão, avaliam que "A análise de impacto de uma política em grande medida se vale dos quantitativos: pessoas atingidas versus recursos investidos. No caso do Proeja, segundo dados do Censo Escolar (INEP, 2012), as matrículas na oferta de EJA integrada à educação profissional chegaram a 54.615 alunos, representando uma queda de mais de 10 mil alunos, comparados aos dados do ano de 2011. O dado de financiamento das ações Proeja pelo governo federal representou o montante, em 2006, de R \$ 16.287.203,18 [...] chegando, em 2010, a $\mathrm{R} \$ 38.438 .262,19$ [...] todavia, não acompanhava o crescimento de matrícula que ocorreu no curto período entre 2007 e 2011. Esses dados por si só representam a impossibilidade do Proeja tornar-se uma política em escala" (MACHADO; RODRIGUES, 2013, p. $380)$.

${ }^{7}$ O Enem, entre 2009 e 2016, tinha também a função de certificação de conclusão do ensino médio.

${ }^{8}$ Machado, abordando todas as etapas da EJA, afirma: "esse é o pior cenário para chegar a 20 anos pós a LDB 1996, quando esperávamos que a EJA se fortalecesse como política pública de Estado" (MACHADO, 2016, p. 444). A autora destaca o esforço realizado que resultou num aumento de matrículas na EJA, nos primeiros dez anos após a LDB, até aproximadamente o ano de 2006, seguido de quedas constantes em todas as etapas, até o ano de 2014 (MACHADO, 2016).

${ }^{9}$ Se levarmos em consideração o pico de matrículas EJA ensino médio (1.650.184 matriculados), atingido no ano de 2008 (TODOS PELA EDUCAÇÃO, 2019, p. 87), a redução supera 210 mil matrículas, quase $13 \%$ inferior aos números de 2008. Se a comparação for com o ano de 2019, em que a lenta tendência de recuperação foi interrompida, as perdas superam 314 mil matrículas, aproximadamente um quinto de matriculados a menos.

${ }^{10}$ Embora tenhamos poucos elementos para uma avaliação mais precisa desse recuo das matrículas em 2019, é razoável considerar que o teto de gastos previsto na Emenda Constitucional 95, o início de administrações estaduais eleitas em 2019 e a gestão de um Presidente da República de orientação ultraliberal influenciaram nessa dinâmica.

${ }^{11}$ Segundo o jornal Estadão, em 2015, essa migração foi de quase 158 mil alunos (PALHARES, 2017); segundo o Inep (BRASIL, 2018a), essa migração foi de 179 mil alunos em 2016 e, em 2019, foi de 200 mil alunos (BRASIL, 2020).

${ }^{12}$ A abertura de possibilidade dessa interferência fica explícita na lei $13.415 / 2017$, no artigo $4^{\circ}$, $\S 11$, em que diz "Para efeito de cumprimento das exigências curriculares do ensino médio, os sistemas de ensino poderão reconhecer competências e firmar convênios com instituições de educação a distância com notório reconhecimento [...]" (BRASIL, 2017b).

${ }^{13}$ Os governos estaduais, ao longo do período, responderam por mais de $80 \%$ dessa oferta.

${ }^{14}$ Ver nota 5.

Educação | Santa Maria | v. 46 |2021

Disponível em: https://periodicos.ufsm.br/reveducacao 


\section{N

ISSN: 1984-6444 | http://dx.doi.org/10.5902/1984644461413

${ }^{15}$ Muitos deles também oferecidos a distância, como, por exemplo, o Programa Nacional de Acesso ao Ensino Técnico e Emprego (Ponatec). Ver Brasil (2011).

${ }^{16}$ Em entrevista, Maria Clara Di Pierro (2015) afirma: "São muitos os desafios. Eu acho que buscar um regime de colaboração mais adequado entre União, Estados e Municípios é um deles. A União não pode renunciar ao seu papel indutor de políticas, mas esse padrão de programas pré-formatados que são oferecidos aos estados e municípios para adesão com pouquíssima flexibilidade acabaram gerando paralelismos e não ajudaram a institucionalizar e a fortalecer a EJA na Educação de Jovens e Adultos no Brasil”.

${ }^{17}$ Primeiro, através da medida provisória no 746/2016 (BRASIL, 2016) e depois regulamentado na lei 13.415/2017 (BRASIL, 2017b), o chamado Novo Ensino Médio instituiu a Política de Fomento à Implementação de Escolas de Ensino Médio em Tempo Integral.

18 A resolução 03/2018 (BRASIL, 2018b) atualizou as Diretrizes Curriculares Nacionais para o ensino médio e, no mesmo ano, foi instaurada a Base Nacional Comum Curricular (BNCC), que não faz referência específica à EJA.

19 Trata-se do decreto 9057/2017 (BRASIL, 2017a), que regulamenta a oferta de cursos a distância para o ensino médio e para a educação profissional técnica de nível médio.

${ }^{20}$ Os resultados do Encceja superaram os do Enem, quando este certificava para o ensino médio (MORENO, 2019). 